\title{
Association of genomically enhanced and parent average breeding values with cow performance in Nordic dairy cattle
}

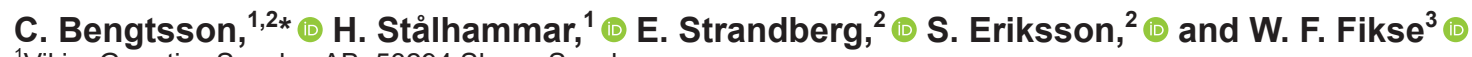 \\ ${ }^{1}$ Viking Genetics Sweden AB, 53294 Skara, Sweden \\ ${ }^{2}$ Department of Animal Breeding and Genetics, Swedish University of Agricultural Sciences, 75007 Uppsala, Sweden \\ ${ }^{3}$ Växa Sverige, 75105 Uppsala, Sweden
}

\begin{abstract}
This study compared the abilities of virgin heifer genomically enhanced breeding values (GEBV) and parent average breeding values (PA) to predict future cow performance. To increase confidence in genomic technology among farmers, a clear demonstration of the relationship between genomic predictions and future phenotypes is needed. We analyzed 12 different traits in first parity, including production, conformation, fertility, and other functional traits. Phenotype data were obtained from national milk recording schemes and breeding values from the Nordic Cattle Genetic Evaluation. Direct genomic breeding values were calculated using genomic BLUP and combined with traditional breeding values, using bivariate blending. The data covered 14,862 Red Dairy Cattle, 17,145 Holstein, and 7,330 Jersey genotyped virgin heifers born between 2013 and 2015 in Denmark, Finland, and Sweden. Phenotypes adjusted for systematic environmental effects were used as measures of cow performance. Two methods were used to compared virgin heifer GEBV and PA regarding their ability to predict future cow performance: (1) correlations between breeding values and adjusted phenotypes, (2) ranking cows into 4 quartiles for their virgin heifer GEBV or PA, and calculating actual cow performance for each quartile. We showed that virgin heifer GEBV predicted cow performance significantly better than PA for the vast majority of analyzed traits. The correlations with adjusted phenotypes were 38 to $136 \%$ higher for GEBV than for PA in Red Dairy Cattle, 42 to $194 \%$ higher for GEBV in Holstein, and 11 to $78 \%$ higher for GEBV in Jersey. The relative change between GEBV bottom and top quartiles compared with that between PA bottom and top quartiles ranged from 9 to $261 \%$ for RDC, 42 to $138 \%$ for Holstein, and 4 to $90 \%$ for Jersey. Hence,
\end{abstract}

Received November 26, 2019

Accepted February 27, 2020.

*Corresponding author: chben@vikinggenetics.com farmers in Denmark, Finland, and Sweden can have confidence in using genomic technology on their herds. Key words: genomic breeding value, genotyping, dairy cow, validation

\section{INTRODUCTION}

To increase confidence in genomic technology among farmers, a clear illustration of the relationship between genomic predictions and future phenotypes is needed (Pryce and Hayes, 2012). In the early years of genomic selection, mainly bulls were tested, but genotyping of virgin heifers has become more interesting as the costs decrease (Calus et al., 2015; Hjortø et al., 2015; Ettema et al., 2017). At herd level, genomic test results can be used to (1) find the best females for breeding and replacement, (2) identify females for embryo transfer or in vitro fertilization, (3) correct parentage assignment, (4) control monogenic traits, and (5) avoid inbreeding through genomic-assisted mating plans (Pryce et al., 2012).

Genomically enhanced breeding values (GEBV) can be validated in different ways. Cross-validation includes dividing the available data set into validation and training sets. By masking observations of all individuals in the validation set and predicting the observations or EBV with a model based on individuals in the training set only, the correlation between masked phenotypes or EBV and predicted values for the validation individuals can be estimated. This correlation then reflects the accuracy of prediction (de Roos et al., 2009). A disadvantage of validating GEBV against conventional EBV is that training and validation sets are rarely strictly independent (Su et al., 2010). Yao et al. (2015) used genotypes and health data to predict future phenotypes, taking correlations between predicted values and phenotypes as measurements of accuracy. To illustrate the accuracy of GEBV compared with parent average breeding values (PA), Weigel et al. (2015) divided cows into quartiles based on their virgin heifer GEBV and sire PTA, and thereafter calculated actual cow performances for each quartile. 
Establishment of the Nordic Cattle Genetic Evaluation in 2002 has led to intensified cooperation between AI organizations in Denmark, Finland, and Sweden (DFS). Because the differences across the Nordic countries were small, according to a study on genotype $x$ environment interactions by Kolmodin et al. (2002), a joint breeding program was established. The current breeding goal combines breeding values for 60 traits into 14 main breeding values, including health, reproduction, production, and conformation.

Genotyping of cows and virgin heifers in DFS started on a large scale in 2012 with the VikingGenetics genotyping project. Three breeds in the DFS countries have genomic breeding schemes: Red Dairy Cattle (RDC), Holstein, and Jersey. Initially, the main purpose was to include genotyped females in the reference population and thereby increase the accuracy of GEBV. This was especially important for RDC and Jersey, which had more limited reference populations based on bulls than did the Holstein breed. In 2018, close to $12 \%$ of females born in DFS were genomically tested, compared with approximately $2 \%$ in 2012, and growth potential for genomic testing remains. To date, over 250,000 females have been genotyped, and phenotypic information from over 100,000 of these animals has been recorded (Nielsen et al., 2019).

Approximately $85 \%$ of farms in DFS are enrolled in the national milk recording schemes. This enables validation of GEBV with phenotype data on a large scale, with a design having the desirable property that the validation population is strictly independent of the training population. The purpose of this study was to compare the abilities of virgin heifer GEBV and PA to predict future cow performance. To our knowledge, this has not previously been done on a large scale in
3 breeds across countries. This could be an important step to convince farmers that genomic breeding values are valuable for use on their herds for selection decisions.

\section{MATERIALS AND METHODS}

\section{Data}

Phenotype data were collected from the DFS milk recording schemes for the 3 breeds (RDC, Holstein, and Jersey). Observations from the first lactation of animals born from 2013 to 2015 were used in the analysis. To be included in the study, all animals were required to have a 305-d milk yield record. The total numbers of genotyped females in the study period with a 305-d milk yield record were 20,274 RDC, 23,910 Holstein, and 9,312 Jersey. We analyzed 12 traits in first parity: 3 milk production traits (milk yield, fat yield, and protein yield), 2 udder health traits (SCS and occurrence of clinical mastitis), 1 fertility trait (interval, in days, from first to last service, IFL), 2 conformation traits (udder, and feet and legs), 1 calving trait (calving ease, CE), 1 survival trait (survival to second calving, survival 1-2), 1 claw health $(\mathbf{C H})$ trait, and 1 general health (GH) trait. Detailed trait definitions can be found in Table 1. For Jersey, it was not possible to analyze CH or GH, because for those traits the genomic evaluation was still under development during the study period.

Female GEBV and PA were obtained from the Nordic Cattle Genetic Evaluation (NAV, 2019). Detailed descriptions of all breeding values can be found in Table 2. Heritability in first lactation of traits used in the Nordic Cattle Genetic Evaluation can be found in Table 3, and in Table 4 average model reliabilities

Table 1. Detailed definitions of the traits studied

\begin{tabular}{ll}
\hline Trait & Phenotype definition (first lactation) \\
\hline Milk yield & 305-d kg of milk yield \\
Fat yield & 305-d kg of fat yield \\
Protein yield & 305-d kg of protein yield \\
SCS & SCC transformed to logarithmic scale \\
Clinical mastitis & Clinical mastitis up to 300 d \\
IFL & Interval in days from first to last service \\
Udder & Total udder conformation score \\
Feet and legs & Total feet and legs conformation score \\
Calving ease (maternal) & First calving, recorded in 4 categories: (1) easy calving without help, (2) easy calving with help, (3) difficult \\
& calving without veterinarian help, and (4) difficult calving with veterinarian help \\
Claw health & Records from first to second calving or up to 430 d after calving in first lactation. Claw disorders included were \\
& sole ulcer, sole hemorrhage, heel horn erosion, digital dermatitis, interdigital dermatitis, verrucose dermatitis, \\
General health & interdigital hyperplasia, double sole, white line separation, and corkscrew claw \\
& Includes retained placenta, hormonal reproductive disorders, infective reproductive disorders, ketosis, milk fever, \\
Survival $1-2^{2}$ & other metabolic diseases, other feed-related disorders, other diseases, and feet and leg problems \\
\hline
\end{tabular}

${ }^{1}$ Defined as 1 if the animal had at least one treatment, 0 otherwise.

${ }^{2}$ Defined as 1 if the animal survived, 0 otherwise. 
Table 2. Detailed definitions of breeding values (NAV, 2019)

\begin{tabular}{|c|c|}
\hline Breeding value & Breeding value definition \\
\hline Fat & Fat production in the first 3 lactations \\
\hline Protein & Protein production in the first 3 lactations \\
\hline Fertility & $\begin{array}{l}\text { Based on number of services, interval from calving to first service, interval from first to last service, non-return rate, } \\
\text { heat strength, and conception rate. Includes records as virgin heifer to the third lactation }\end{array}$ \\
\hline Feet and legs & $\begin{array}{l}\text { Linear traits combined into a group describing feet and leg conformation. Includes the linear conformation traits } \\
\text { rear legs (side view), rear legs (rear view), hock quality, bone quality, and foot angle. Based on data from the first } 3 \\
\text { lactations }\end{array}$ \\
\hline Calving (maternal) & $\begin{array}{l}\text { Including calving ease and calf survival in the first } 24 \mathrm{~h} \text {. Calving is recorded in } 4 \text { categories, as for the phenotype } \\
\text { trait (Table 1). Calf survival is defined as } 1 \text { if the calf survived, } 0 \text { otherwise. Includes records from first to fifth } \\
\text { calving }\end{array}$ \\
\hline
\end{tabular}

for genotyped animals can be found. Breeding values from 36 evaluations performed between August 2014 and February 2017 were used in this study. The GEBV and PA used were based on the breeding values estimated closest in time to when the animal reached $1 \mathrm{yr}$ of age. Eleven different GEBV and PA were used: milk, fat, protein, udder health, fertility, udder, feet and leg, calving (maternal), claw health, general health, and longevity. These breeding values correspond to the phenotypes listed in Table 1 but are not defined in exactly the same way. Breeding values were based on multiple lactations, whereas phenotypes were from the first lactation only. The breeding values studied

Table 3. Heritability in first lactation of traits used in the Nordic cattle genetic evaluation (NAV, 2019) ${ }^{1}$

\begin{tabular}{|c|c|c|c|}
\hline Trait & $\mathrm{RDC}$ & Holstein & Jersey \\
\hline Milk & 0.41 & 0.43 & 0.44 \\
\hline Fat & 0.35 & 0.36 & 0.35 \\
\hline Protein & 0.41 & 0.35 & 0.38 \\
\hline $\mathrm{SCC}$ & 0.12 & 0.13 & 0.11 \\
\hline Clinical mastitis & 0.04 & 0.05 & 0.04 \\
\hline IFL & 0.03 & 0.03 & 0.03 \\
\hline Udder & 0.25 & 0.25 & 0.25 \\
\hline Feet and legs & 0.20 & 0.20 & 0.20 \\
\hline Calving ease & 0.04 & 0.06 & 0.02 \\
\hline Claw health ${ }^{2}$ & $0.001-0.040$ & $0.004-0.070$ & $0.000-0.070$ \\
\hline General health ${ }^{2}$ & $0.003-0.01$ & $0.004-0.034$ & $0.004-0.013$ \\
\hline Survival $1-2^{3}$ & 0.04 & 0.05 & 0.05 \\
\hline
\end{tabular}

${ }^{1} \mathrm{RDC}=$ Red Dairy Cattle; IFL $=$ interval from first to last service, in days.

${ }^{2}$ The interval represents the range of heritability for the included subtraits (Table 1 ).

${ }^{3}$ Heritability for survival from first to second calving. are also combinations of several underlying component traits (e.g., the fertility breeding value also includes information on the interval in days between calving and first service). We calculated GEBV using bivariate blending of direct genomic values and traditional EBV (Mäntysaari and Strandén, 2010; Taskinen et al., 2013). In September 2015, the calculation of direct genomic breeding values changed from GBLUP to SNPBLUP (Nielsen et al., 2016), which was shown to give comparable results (Koivula et al., 2012). Detailed breeding value calculations can be found in NAV (2019).

To prevent virgin heifer reproductive performance from influencing the fertility breeding values used in this study, breeding values estimated after 14 mo of age were not included. For the same reason, animals genotyped after 14 mo were excluded. At the beginning of the VikingGenetics genotyping project, it was common to genotype animals up to the second lactation.

Table 4. Average model reliabilities (\%) published for genotyped animals, 1 to 2 yr old, born in 2017 [Gert Pedersen Aamand, Executive Director, Nordic Cattle Genetic Evaluation (NAV, Aarhus, Denmark), personal communication, June 26, 2019]; RDC = Red Dairy Cattle

\begin{tabular}{lccc}
\hline Breeding value & RDC & Holstein & Jersey \\
\hline Yield & 74 & 77 & 71 \\
Udder health & 66 & 74 & 63 \\
Fertility & 59 & 74 & 55 \\
Udder & 66 & 73 & 64 \\
Feet and legs & 66 & 66 & 57 \\
Calving & 54 & 68 & 43 \\
Claw health & 51 & 59 & 46 \\
General health & 50 & 58 & 45 \\
Longevity & 49 & 66 & 44 \\
\hline
\end{tabular}


Consequently, most of the animals removed were born in 2013, which was the first year analyzed in this study. However, in the last 2 years studied, 2014 and 2015, most animals were genotyped as virgin heifers and were therefore included in the study. The number of genotyped animals also increased over the study period. Hence, most of the animals studied were born in 2014 and 2015. The numbers of genotyped animals in the birth year cohort studied (2013 to 2015), genotyped before 14 mo of age and with a 305-d milk yield record, were 14,862 RDC from 900 herds, 17,145 Holstein from 1,960 herds, and 7,330 Jersey from 235 herds.

\section{Statistical Analysis}

To obtain adjusted phenotypes for use in analysis of the predictive ability of breeding values, a larger phenotype data set was analyzed using Statistical Analysis Software (SAS) version 9.4 (SAS Institute Inc., Cary, $\mathrm{NC}$ ). This analysis included all animals in the milk recording scheme born from 2008 to 2016, which, in total, comprised 997,797 RDC, 2,322,514 Holstein, and 240,946 Jersey. The adjusted phenotypes - that is, residual effects estimated using PROC HP MIXED with the linear model [1] described below-were named according to the respective trait; for example, adjusted

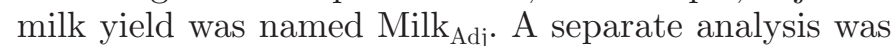
performed for each breed.

The following linear model was used for all traits:

$$
\mathrm{y}_{\mathrm{ijk} k m n}=\mu+\mathrm{HY}_{\mathrm{ij}}+\mathrm{YMC}_{\mathrm{jkl}}+\mathrm{CCA}_{\mathrm{lm}}+\mathrm{e}_{\mathrm{ijk} \mathrm{kmn}},
$$

where $\mathrm{y}_{\mathrm{ijk} \text { lmn }}$ is the observed phenotypic value in first lactation; $\mu$ is mean of the population; $\mathrm{HY}_{\mathrm{ij}}$ is the fixed class effect of herd i and calving year $\mathrm{j}$ (2008 through 2018); $\mathrm{YMC}_{\mathrm{jkl}}$ is the fixed class effect of calving year $\mathrm{j}$, month k (1 through 12), and country l (Denmark, Finland, or Sweden); $\mathrm{CCA}_{\operatorname{lm}}$ is the fixed class effect of country $l$ and calving age in months as heifer $\mathrm{m}$ (18 to $36)$; and $\mathrm{e}_{\mathrm{ijklmn}}$ is the random residual, $\sim N D\left(0, \sigma_{e}^{2}\right)$.

We used $\mathrm{HY}_{\mathrm{ij}}+\mathrm{YMC}_{\mathrm{jkl}}$ as contemporary groups due to small average herd size, making it difficult to use herd-year-month or herd-year-season. Country was not included in the model for Jersey, because all Jersey cows studied were located in Denmark. For further analyses, the PROC MEANS and PROC FREQ procedures in SAS were used for descriptive statistics.

Because breeding values were obtained from several routine evaluations separated in time, they were not directly comparable due to rolling base population. Linear regression analysis was used to adjust for genetic trends over time. In PROC REG, the regression coefficient was estimated between breeding values in a given evaluation and the corresponding breeding values in the last evaluation (February 2017). The linear regression model used was

$$
\mathrm{y}_{\mathrm{i}}=\mathrm{b}_{0}+\mathrm{b}_{1} \mathrm{X}+\mathrm{e}_{\mathrm{ij}}
$$

where $\mathrm{y}_{\mathrm{i}}$ is a breeding value in the last evaluation (February 2017); $b_{0}$ is the intercept; $b_{1}$ is the regression coefficient on the corresponding breeding value $(\mathrm{X})$ in a breeding evaluation performed from August 2014 to January 2017; and $\mathrm{e}_{\mathrm{ij}}$ is the random residual, $\sim N D\left(0, \sigma_{e}^{2}\right)$. Breeding values were then expressed on the scale of the last evaluation, using the estimated regression parameters from Model [2] using PROC SCORE.

PROC CORR was used to calculate the correlation between breeding values (PA or GEBV) and adjusted phenotypes for each of the breeds. A 95\% confidence interval using Fisher's Z transformation was used to assess the significance of the difference between correlations. The PROC RANKS procedure was used to rank cows into 4 quartiles across herds for GEBV or PA.

\section{RESULTS}

For RDC and Holstein, all correlations between breeding values and adjusted phenotypes were significantly stronger for GEBV than for PA (Table 5). For Jersey, GEBV correlations were significantly stronger for all traits except clinical mastitis, $\mathrm{CE}$, and survival 1-2. The correlations with adjusted phenotypes were 42 to $194 \%$ higher for GEBV than for PA in RDC, 38 to $136 \%$ higher for GEBV in Holstein, and 11 to $78 \%$ higher for GEBV in Jersey for the different traits (Table 5). All correlations between PA and adjusted phenotypes were significantly different from zero. The highest correlation found in this study was between

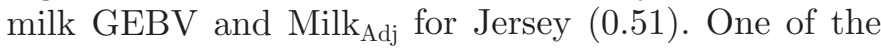
traits for which the correlations increased the most, $\mathrm{IFL}_{\text {Adj }}$ increased by over $64 \%$ for all 3 breeds when genomic information was included in the breeding values. For Jersey, the correlation between breeding value and $\mathrm{IFL}_{\text {Adj }}$ increased by $78 \%$ when genomic information was included.

The relative change between the GEBV bottom and top quartile $(\boldsymbol{G}$ GEBV $)$ compared with that between the PA bottom and top quartile $(\boldsymbol{\Delta} \mathbf{P A})$, ranged from 9 to $261 \%$ for RDC, 42 to $138 \%$ for Holstein, and 4 to $90 \%$ for Jersey (Table 6). However, it should be noted that the large relative percentage change between PA and GEBV for both quartiles and correlations was, in many cases, from initially low levels. 


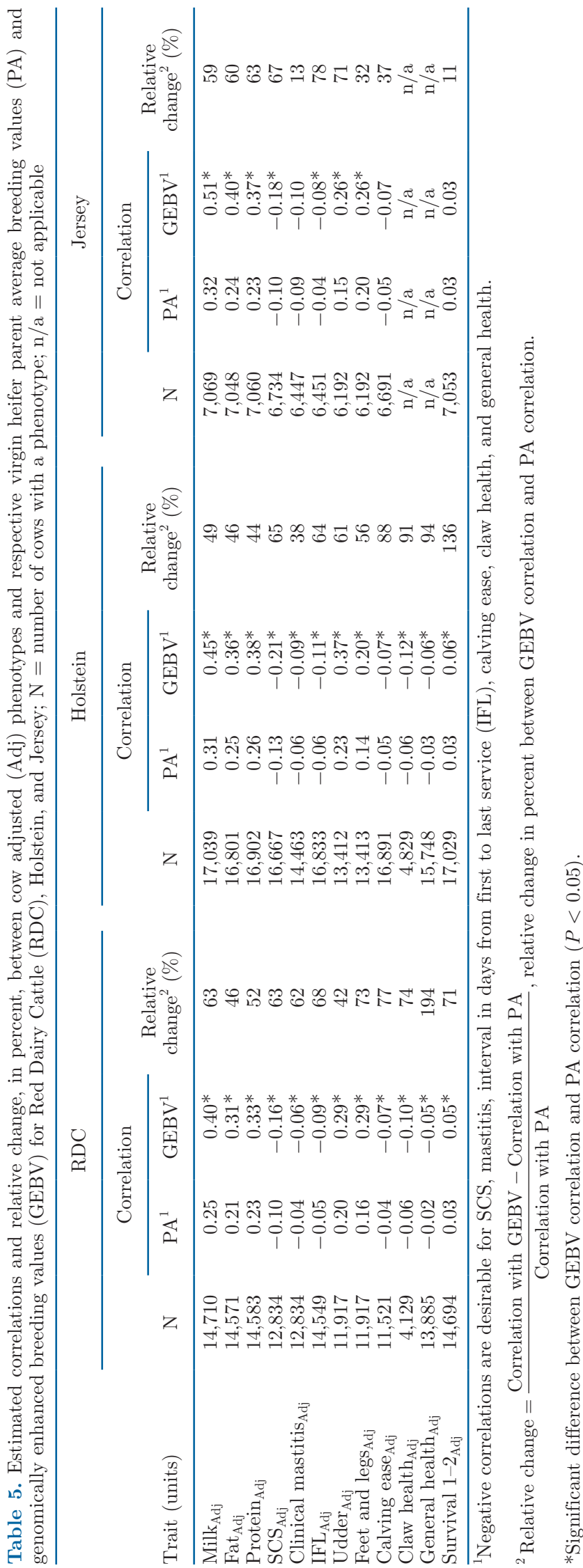

\section{DISCUSSION}

An advantage of using phenotypes for validation of breeding values is that it makes it easy for farmers to understand how their animals' breeding values work in practice, when validation is against their own farm records. The use of phenotypes in this study was facilitated by the high rate of participation in the national milk recording schemes in the DFS countries. The extracted virgin heifer GEBV and PA, estimated before on-farm information was recorded, reflected information available to farmers at the time of selection. The maximum age at which a breeding value for a heifer was taken was $14 \mathrm{mo}$, to reflect the breeding values at first insemination for virgin heifers. For example, at that age the farmer can combine genomic selection with decisions about sexed and beef semen, as suggested in other studies (Hjortø et al., 2015; Ettema et al., 2017).

Many of the breeding values used in the present study are combinations of several underlying component traits. For example, the udder health breeding value includes data on clinical mastitis, SCC, udder attachment, and udder depth. Furthermore, most of the breeding values are based on the first 3 lactations and not only the first lactation, whereas the phenotypes studied were only from the first lactation. These 2 factors most likely resulted in somewhat weaker relationships between breeding values and phenotypes than if sub-trait breeding values for the first lactation had been used. However, those breeding values were not available for this study nor for the farmers in the studied period. Nevertheless, these factors probably had a limited influence on the relative change between GEBV and PA, which was the focus in this study.

We chose to use linear models for all traits, to represent current practice in the Nordic genetic evaluation. However, some traits could be claimed to be theoretically less well suited for a linear model, such as clinical mastitis, survival 1-2, and CE. Therefore, we tried different models to fit the data (binary distribution, Poisson distribution) in preliminary analyses for the Jersey breed, but the results were similar to those obtained using linear models.

The highest correlations obtained in this study were between production traits and breeding values. This could be expected, as production traits have the highest heritability and reliability of the traits studied (Tables 3 and 4). Mathematically, the correlation between the true breeding value and phenotype is equal to $h$, and the proportion of variance explained by the breeding value is $\mathrm{h}^{2}$. However, we did not have the true breeding values in this study, and therefore the expected (squared) correlation equals the product of heritability and reliability. 
Table 6. Differences in averages of adjusted (Adj) phenotypes between cows in bottom and top quartiles for virgin heifer parent average breeding values $(\triangle \mathrm{PA})$, genomically enhanced breeding values $(\triangle \mathrm{GEBV})$, and relative change in percent, respectively, for Red Dairy Cattle (RDC), Holstein, and Jersey; for trait definitions, see Table $1 ; \mathrm{n} / \mathrm{a}=$ not applicable

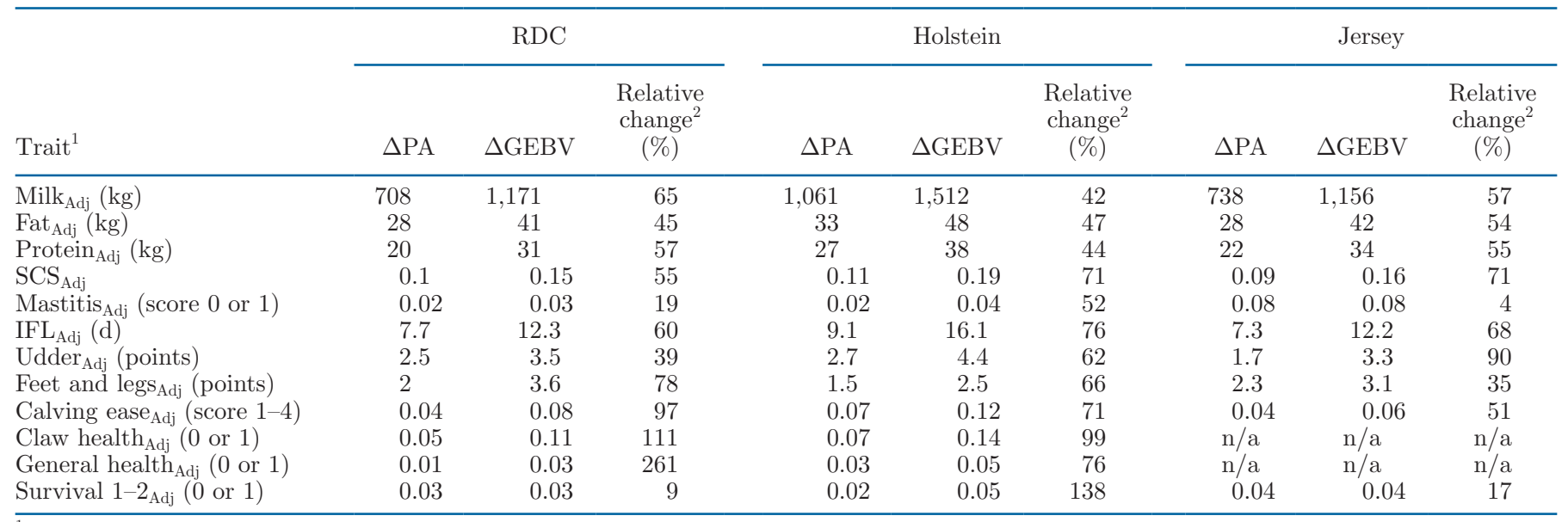

${ }^{1} \mathrm{IFL}=$ interval from first to last service, in days.

${ }^{2}$ Relative change $=\frac{\Delta \mathrm{GEBV}-\Delta \mathrm{PA}}{\Delta \mathrm{PA}}$, relative change in percent between GEBV bottom and top quartile compared with PA bottom and top quartile.

The correlations with adjusted phenotypes were over $40 \%$ stronger for all production traits and breeds when genomic information was used compared with PA. The highest correlation found in this study was between

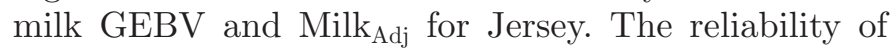
the yield breeding values differed least from each other (Table 4), where the heritability for RDC was slightly lower than for Holstein and Jersey (Table 3). The Nordic RDC is the most genetically diverse of the 3 breeds studied, as it is a mixture of Swedish Red, Danish Red, and Finnish Ayrshire and also includes genes from Norwegian Red, Canadian Ayrshire, American Brown Swiss, and Red Holstein Friesian (NAV, 2019). Hence, less linkage disequilibrium between markers and quantitative trait loci could explain the lower correlations for RDC. The difference between top and bottom quartiles in adjusted phenotypes when using GEBV instead of PA ( $\triangle$ GEBV - $\triangle \mathrm{PA}$; Table 6$)$ for Milk $\mathrm{Adj}_{\mathrm{A}}$ was lower than that reported by Weigel et al. (2015). For Holstein, the difference in our study was $+450 \mathrm{~kg}$ with genomic information, compared with $+1,104 \mathrm{~kg}$ in Weigel et al. (2015). However, only sire PTA (rather than PA) values were used in their study, and the results were only from 411 cows. Additionally, differences in production level and phenotypic variance most likely occurred between our study and that of Weigel et al. (2015).

In general, traits with low heritability in the present study, such as IFL, clinical mastitis, $\mathrm{CE}, \mathrm{CH}$, and GH, gained relatively more in accuracy from using genomic information than did highly heritable traits such as production. The same pattern has been reported by other studies (García-Ruiz et al., 2016; Wiggans et al., 2017).

In our study, $\mathrm{IFL}_{\mathrm{Adj}}$ was one of the traits for which correlations increased the most when genomic information was included in the breeding values (over 60\% for all 3 breeds). It has been established that IFL has the strongest correlation with fertility breeding value (NAV, 2019). For Jersey, the correlation between breeding value and $\mathrm{IFL}_{\mathrm{Adj}}$ increased by $78 \%$ when genomic information was included. Looking at the quartiles for IFL, the difference between $\triangle \mathrm{GEBV}$ and $\triangle \mathrm{PA}$ was 4.6 to $7.0 \mathrm{~d}$ in favor of GEBV (Table 6). Consequently, virgin heifer GEBV was more effective than PA in identifying cows with poor and good fertility.

Our results also confirmed that GEBV can help in choosing animals with better udder health. The correlation between SCS $_{\text {Adj }}$ and GEBV increased by over $55 \%$ compared with $\mathrm{SCS}_{\text {Adj }}$ and PA for all 3 breeds. The udder health trait with the highest heritability is SCS (Table 3), and one could expect a stronger correlation compared with clinical mastitis. Weigel et al. (2015) found that SCS showed almost no difference between quartiles for PA, even though their study had greater differences between quartiles for genomic values. In the present study, we also found significant differences for correlations between Clinical Mastitis Adj $_{\text {and }}$ udder health breeding values for Holstein and RDC but not for Jersey. However, the Jersey correlation between PA udder health and Mastitis Adj $_{\text {was }}$ relatively strong, which indicates that the conventional evaluation works well for this trait, possibly owing to higher clinical mastitis frequency among Jersey cows than among 
Holstein and RDC cows (Appendix Tables A1 and A2). In the genotyped data set, the clinical mastitis frequency for Jersey was $17 \%$, compared with $7 \%$ for Holstein and $6 \%$ for RDC. This was also reflected in the differences between quartiles, where both $\triangle \mathrm{PA}$ and $\triangle$ GEBV differences were larger for Jersey. However, we found no differences between PA and GEBV in their ability to predict the future adjusted phenotype for Jersey (Table 6). The low clinical mastitis frequencies for RDC and Holstein made it more difficult to detect differences between GEBV and PA. The correlations between breeding values for udder health and clinical mastitis are stronger in the second and third lactations (NAV, 2019). It would have been interesting to study the second and third lactations, but for most animals these had not been completed at the time of this study.

For RDC and Holstein, we discovered significantly stronger correlations between calving GEBV and $\mathrm{CE}_{\mathrm{Adj}}$ than between calving PA and $\mathrm{CE}_{\mathrm{Adj}}$. However, with fewer genotyped heifers and some animals lacking $\mathrm{CE}$ information, it was not possible to draw a similar conclusion for Jersey. Analysis also revealed fewer calving problems for Jersey, for which the score was on average 1.06 in the genotyped group, compared with 1.24 for RDC and 1.23 for Holstein (Appendix Tables A1 and A2). Further, heritability and GEBV reliability were also lower for the calving trait in Jersey compared with Holstein and RDC (Tables 3 and 4), which might explain why it was not possible to detect significant differences between GEBV correlation and PA correlation. The difference between quartiles was also smaller for Jersey $(+0.02)$ compared with RDC $(+0.04)$ and Holstein $(+0.05)$ when genomic information was included in the breeding value (Table 6).

Phenotypes for both conformation traits were significantly more strongly correlated with conformation GEBV than with conformation PA. On examining the difference between conformation quartiles (Table 6), it was also possible to see that the prediction improved when genomic information was included. The difference between the top and bottom $25 \%(\Delta \mathrm{GEBV}-\Delta \mathrm{PA})$ increased by between 0.8 and 1.6 scoring points for feet and leg conformation, and between 1.0 and 1.7 scoring points for udder conformation, when genomic information was used (Table 6). Thus, GEBV can be more effective than PA in predicting future conformation.

We also disovered a lack of phenotypes for the $\mathrm{CH}$ trait (Table 5), which might have affected the results for that trait. Nevertheless, for both RDC and Holstein, the correlations between $\mathrm{CH}$ GEBV and $\mathrm{CH}_{\text {Adj }}$ were significantly stronger than the correlations between $\mathrm{CH}$ $\mathrm{PA}$ and $\mathrm{CH}_{\mathrm{Adj}}$. For Jersey, it was not possible to compare GEBV and PA regarding their ability to predict future cow claw health, because the genomic evaluation for $\mathrm{CH}$ in that breed was only established in 2018.

For both Holstein and RDC, the correlations between general health GEBV and $\mathrm{GH}_{\mathrm{Adj}}$ were significantly stronger than the correlations between general health $\mathrm{PA}$ and $\mathrm{GH}_{\mathrm{Adj}}$. The correlations between $\mathrm{GH}$ breeding value and $\mathrm{GH}_{\mathrm{Adj}}$ increased by $99 \%$ for Holstein and $194 \%$ for RDC when using genomic selection. From the quartile differences $(+0.02)$ for both Holstein and RDC, the benefit of using genomic selection was not equally clear. The heritability of the GH trait is low, and the trait is influenced by the environment to a large extent (Table 3). For GH, the genomic evaluation for Jersey was under development at the time of the study.

For RDC and Holstein, significantly stronger correlations occurred between longevity GEBV and Survival $1-2_{\text {Adj }}$ than between longevity PA and Survival $1-2_{\text {Adj }}$. For Jersey, we found no differences between the abilities of GEBV and PA to predict future survival performance. Further, looking at differences between the quartiles $(\triangle \mathrm{GEBV}-\Delta \mathrm{PA})$ for Holstein $(+0.03)$, Jersey $( \pm 0)$ and RDC $( \pm 0)$, it was not possible to see the benefit of genomic selection for RDC and Jersey (Table 6). The reliability of survival GEBV was also lower for Jersey than for Holstein and RDC (Table 4). Survival is strongly affected by farmer decisions, the environment, and other functional and health traits (Kargo et al., 2014), which also could explain the results. It would have been interesting to study survival in later lactations. The longevity breeding value includes data to the end of the fifth lactation, and the correlations between longevity breeding value and survival are stronger in later lactations (NAV, 2019).

\section{CONCLUSIONS}

We showed that virgin heifer GEBV predicted cow performance significantly better than did PA for the vast majority of analyzed traits in Red Dairy Cattle, Jersey, and Holstein. Thus, farmers in Denmark, Finland, and Sweden can have confidence in using genomic technology on their herds for selection decisions. Traits with low heritability, such as interval from first to last insemination, clinical mastitis, calving ease, claw health, and general health, gained relatively more from inclusion of genomic information than did highly heritable traits such as production.

\section{ACKNOWLEDGMENTS}

This study was funded by the Swedish project LivsID - Externally employed doctoral students within food-related research. We offer special thanks to Faba 
(Hollola, Finland), Nordic Cattle Genetic Evaluation (Aarhus, Denmark), SEGES (Aarhus, Denmark), and Växa Sverige (Uppsala, Sweden) for providing us with data. The authors have not stated any conflicts of interest.

\section{REFERENCES}

Calus, M. P. L., P. Bijma, and R. F. Veerkamp. 2015. Evaluation of genomic selection for replacement strategies using selection index theory. J. Dairy Sci. 98:6499-6509. https://doi.org/10.3168/jds .2014-9192.

de Roos, A. P. W., B. J. Hayes, and M. E. Goddard. 2009. Reliability of genomic predictions across multiple populations. Genetics 183:1545-1553. https://doi.org/10.1534/genetics.109.104935.

Ettema, J. F., J. R. Thomasen, L. Hjortø, M. Kargo, S. Østergaard, and A. C. Sørensen. 2017. Economic opportunities for using sexed semen and semen of beef bulls in dairy herds. J. Dairy Sci. 100:4161-4171. https://doi.org/10.3168/jds.2016-11333.

García-Ruiz, A., J. B. Cole, P. M. VanRaden, G. R. Wiggans, F. J. Ruiz-López, and C. P. Van Tassell. 2016. Changes in genetic selection differentials and generation intervals in US Holstein dairy cattle as a result of genomic selection. Proc. Natl. Acad. Sci. 113:E3995-E4004. https://doi.org/10.1073/pnas.1519061113

Hjortø, L., J. F. Ettema, M. Kargo, and A. C. Sørensen. 2015. Genomic testing interacts with reproductive surplus in reducing genetic lag and increasing economic net return. J. Dairy Sci. 98:646-658. https://doi.org/10.3168/jds.2014-8401.

Kargo, M., L. Hjort $\varnothing$, M. Toivonen, J. A. Eriksson, G. P. Aamand, and J. Pedersen. 2014. Economic basis for the Nordic Total Merit Index. J. Dairy Sci. 97:7879-7888. https://doi.org/10.3168/jds.2013 -7694 .

Koivula, M., I. Strandén, G. Su, and E. A. Mäntysaari. 2012. Different methods to calculate genomic predictions - Comparisons of BLUP at the single nucleotide polymorphism level (SNP-BLUP), BLUP at the individual level (G-BLUP), and the one-step approach (HBLUP). J. Dairy Sci. 95:4065-4073. https://doi.org/10.3168/jds .2011-4874

Kolmodin, R., E. Strandberg, P. Madsen, J. Jensen, and H. Jorjani. 2002. Genotype by environment interaction in Nordic dairy cattle studied using reaction norms. Acta Agric. Scand. Sect. A-Anim. Sci. 52:11-24. https://doi.org/10.1080/09064700252806380.

Mäntysaari, E. A., and I. Strandén. 2010. Use of bivariate EBV-DGV model to combine genomic and conventional breeding value evaluations. Proc. 9th World Congr. Genet. Appl. Livest. Prod., Leipzig, Germany. http://www.nordicebv.info/wp-content/uploads/2015/ 04/Use-of-bivariate-EBV-DGV-model-to-combine-genomic.pdf

NAV (Nordic Cattle Genetic Evaluation). 2019. NAV routine evaluation 5. Accessed Jan. 14, 2020. https://www.nordicebv.info/ wp-content/uploads/2019/06/NAV-routine-genetic-evaluation -04062019.pdf.
Nielsen, U. S., G. P. Pedersen, J. Pösö, and L. P. Sørensen. 2016. Status and plans - Genomic prediction and traditional evaluation. NAV Workshop 2016. Accessed Jan. 14, 2020. http://nordicebv .info/wp-content/uploads/2016/01/Workshop_2016-Genomic -prediction-and-traditional-evaluation-USN-GAP.pdf.

Nielsen, U. S., G. P. Pedersen, and L. P. Sørensen. 2019. Status and plans - Genomic prediction. NAV Workshop 2019. Accessed Jan. 14, 2020. https://www.nordicebv.info/wp-content/uploads/2019/ 01/Genomic-prediction-USN-NAV-workshop-jan-2019.pdf.

Pryce, J., and B. Hayes. 2012. A review of how dairy farmers can use and profit from genomic technologies. Anim. Prod. Sci. 52:180. https://doi.org/10.1071/AN11172.

Pryce, J. E., B. J. Hayes, and M. E. Goddard. 2012. Genotyping dairy females can improve the reliability of genomic selection for young bulls and heifers and provide farmers with new management tools. In Proc. 38th International Committee for Animal Recording (ICAR) Session, May 28-June 1, 2012, Cork, Ireland. http://www .icar.org/Cork_2012/Manuscripts/Published/Pryce\%202.pdf.

Su, G., B. Guldbrandtsen, V. R. Gregersen, and M. S. Lund. 2010. Preliminary investigation on reliability of genomic estimated breeding values in the Danish Holstein population. J. Dairy Sci. 93:1175-1183. https://doi.org/10.3168/jds.2009-2192.

Taskinen, M., E. A. Mäntysaari, M. H. Lidauer, T. Knürr, J. Pösö, G. $\mathrm{Su}$, G. P. Aamand, and I. Strandén. 2013. Comparison of model reliabilities from single-step and bivariate blending methods. Interbull Bull. 6:246-251. https://jukuri.luke.fi/bitstream/handle/ 10024/481814/1331-2230-1-PB.pdf?sequence=1.

Weigel, K. A., A. A. Mikshowsky, and V. E. Cabrera. 2015. Effective use of genomics in sire selection and replacement heifer management. In Proc. Western Dairy Management Conference, Reno, NV. http://www.wdmc.org/2015/Weigel.pdf.

Wiggans, G. R., J. B. Cole, S. M. Hubbard, and T. S. Sonstegard. 2017. Genomic selection in dairy cattle: The USDA experience Annu. Rev. Anim. Biosci. 5:309-327. https://doi.org/10.1146/ annurev-animal-021815-111422.

Yao, C., L. E. Armentano, M. J. VandeHaar, and K. A. Weigel. 2015. Short communication: Use of single nucleotide polymorphism genotypes and health history to predict future phenotypes for milk production, dry matter intake, body weight, and residual feed intake in dairy cattle. J. Dairy Sci. 98:2027-2032. https://doi.org/ $10.3168 /$ jds.2014-8707.

\section{ORCIDS}

C. Bengtsson () https://orcid.org/0000-0001-5784-2557

H. Stålhammar () https://orcid.org/0000-0002-7354-651X

E. Strandberg (๑) https://orcid.org/0000-0001-5154-8146

S. Eriksson ( ) https://orcid.org/0000-0003-3357-5065

W. F. Fikse @ https://orcid.org/0000-0003-0578-0184 


\section{APPENDIX}

Table A1. First-lactation descriptive statistics [average, SD, and number of animals (N)] for all animals born in 2013, 2014, and 2015 in Denmark, Finland, and Sweden

\begin{tabular}{|c|c|c|c|c|c|c|c|c|c|}
\hline Trait $^{1}$ & \multicolumn{3}{|c|}{ Red Dairy Cattle } & \multicolumn{3}{|c|}{ Holstein } & \multicolumn{3}{|c|}{ Jersey } \\
\hline Fat yield (kg) & 355 & 63 & 210,289 & 363 & 63 & 592,887 & 371 & 61 & 61,100 \\
\hline Protein yield $(\mathrm{kg})$ & 288 & 50 & 210,295 & 308 & 53 & 592,914 & 259 & 43 & 61,105 \\
\hline SCS & 0.68 & 0.42 & 200,178 & 0.67 & 0.37 & 553,293 & 0.8 & 0.37 & 57,807 \\
\hline Clinical mastitis (score 0 or 1 ) & 0.06 & 0.24 & 182,038 & 0.09 & 0.29 & 495,373 & 0.16 & 0.37 & 52,458 \\
\hline Feet and legs (points) & 80.02 & 5.34 & 96,288 & 80.18 & 4.99 & 244,144 & 80.07 & 5.5 & 38,496 \\
\hline Calving ease (maternal; score $1-4$ ) & 1.24 & 0.52 & 139,956 & 1.23 & 0.5 & 471,599 & 1.06 & 0.32 & 55,967 \\
\hline Claw health ( 0 or 1$)$ & 0.51 & 0.5 & 45,466 & 0.64 & 0.48 & 144,002 & 0.51 & 0.5 & 13,225 \\
\hline General health ( 0 or 1$)$ & 0.12 & 0.32 & 185,577 & 0.16 & 0.36 & 519,512 & 0.15 & 0.36 & 54,258 \\
\hline Survival $1-2(0$ or 1$)$ & 0.66 & 0.47 & 212,226 & 0.69 & 0.46 & 588,990 & 0.73 & 0.44 & 60,921 \\
\hline
\end{tabular}

${ }^{1} \mathrm{IFL}=$ interval from first to last service.

Table A2. First-lactation descriptive statistics [average, SD, and number of animals (N)] for all animals genotyped and qualified for analysis born in 2013, 2014, and 2015 in Denmark, Finland, and Sweden

\begin{tabular}{|c|c|c|c|c|c|c|c|c|c|}
\hline Trait $^{1}$ & \multicolumn{3}{|c|}{ Red Dairy Cattle } & \multicolumn{3}{|c|}{ Holstein } & \multicolumn{3}{|c|}{ Jersey } \\
\hline Fat yield $(\mathrm{kg})$ & 374 & 56 & 14,571 & 383 & 58 & 16,801 & 384 & 55 & 7,048 \\
\hline Protein yield (kg) & 306 & 45 & 14,583 & 329 & 51 & 16,902 & 269 & 40 & 7,060 \\
\hline SCS & 0.64 & 0.40 & 12,834 & 0.61 & 0.35 & 16,667 & 0.76 & 0.36 & 6,734 \\
\hline Clinical mastitis (score 0 or 1 ) & 0.06 & 0.24 & 12,834 & 0.07 & 0.27 & 14,463 & 0.17 & 0.36 & 6,447 \\
\hline Feet and legs (points) & 80.12 & 5.26 & 11,917 & 81.06 & 4.71 & 13,413 & 80.80 & 5.21 & 6,192 \\
\hline Calving ease (maternal; score $1-4$ ) & 1.22 & 0.5 & 11,521 & 1.23 & 0.50 & 16,891 & 1.07 & 0.33 & 6,691 \\
\hline Claw health ( 0 or 1$)$ & 0.54 & 0.50 & 4,129 & 0.59 & 0.49 & 4,829 & 0.55 & 0.49 & 1,096 \\
\hline General health ( 0 or 1$)$ & 0.15 & 0.35 & 13,885 & 0.14 & 0.35 & 15,748 & 0.15 & 0.35 & 6,626 \\
\hline Survival $1-2(0$ or 1$)$ & 0.69 & 0.46 & 14,694 & 0.71 & 0.45 & 17,029 & 0.75 & 0.43 & 7,053 \\
\hline
\end{tabular}

${ }^{1} \mathrm{IFL}=$ interval from first to last service. 